\title{
Rural mental health
}

\author{
Alain Gregoire and Graham Thornicroft
}

"He likes the country, but in truth must own, Most likes it when he studies it in town." (William Cowper. 1731-1800)

A romanticised ideal of rural life has been pervasive among the privileged members of our society for at least three centuries. The paintings of Constable and the country house retreats of the urban rich are a historical testimony to this thinking. This view of our society gives rise to assumptions which continue to influence Government policies in a wide variety of areas including transport, employment, education and health. Although one-fifth of the UK population lives in rural areas, health services have tended to concentrate clinical resources and expertise in the larger metropolitan areas and, not surprisingly, medical research has followed suit. Despite the wealth of literature on the links between urban forms of deprivation and a wide range of health problems, there is not adequate data to support any definitive statements about rural/ urban patterns of physical disease (Watt et al, 1993) and we know even less about rural mental health.

\section{Defining rurality}

There is no universally agreed definition of rurality. The concept encompasses ideas such as population density, social and physical environment and land use. What constitutes a rural environment is inevitably relative, particularly internationally - rurality in England is quite different to rurality in Australia.

In the UK, various definitions have been applied using population density (Shucksmith. 1990: Rural Development Commission, 1994), complex indices (Cloke, 1977) and arbitrary judgement by research worker (Meltzer et al, 1995). In such circumstances, it is clear that researchers must select a method of defining rurality which is appropriate to the study being conducted and define this clearly when presenting results.

\section{Psychiatric morbidity}

Rapidly increasing homelessness, lack of supported housing, social isolation, stigma, poor or non-existent transport and inaccessibility or absence of services are characteristics of rural areas (Bentham \& Haynes, 1986; Shucksmith et al, 1996) which do not fit comfortably with the popular (and professional) assumptions that the rural environment offers protection from mental illness.

In 1984, Webb critically reviewed the literature and concluded that there was little evidence of significant rural/urban differences in psychiatric morbidity. A major difficulty in evaluating this literature is the complexity of the different factors operating and the over-generalised concept of a simple rural/urban comparison. The more recent literature allows us to begin to unpick some of the detail and extract more meaningful conclusions by examining the influence of factors such as culture/nationality, diagnostic groups, ethnicity/race, occupation/ social class and geographic/clustering effects.

\section{Different countries - different effects}

Striking differences between countries emerge in the patterns of overall psychiatric morbidity between towns and countryside and it is clear from the variations between countries that findings from international studies cannot be generalised to the UK (Studies examining general psychiatric morbidity. Urban > Rural, Bowling \& Farquhar, 1991 (UK), Lewis \& Booth, 1994 (UK); Urban < Rural, Lee et al, 1990 (Korea), Guinness, 1992 (Swaziland); Urban=Rural, Gyllenhammar et al, 1988 (Sweden), Cheng, 1989 (Taiwan), McGee et al, 1991 (New Zealand), Romans et al. 1992 (New Zealand)).

\section{Diagnosis}

Finding are no more consistent in studies examining particular diagnoses (Table 1).

However, the fairly robust methodologies of some of the studies give credibility to their individual findings. For example, among the UK studies, the Office of Population Censuses and Surveys survey of psychiatric morbidity in nearly 10000 adults in private households (Meltzer et al, 1995) found significantly higher prevalences in urban areas of depression (Odds ratio (OR) 1.38), anxiety disorder $(O R=1.30)$ and phobla $(O R=1.66)$ but no significant differences in obsessive-compulsive disorder, panic, alcohol and drug dependency or psychosis, although in the latter case numbers were very small. Rurality 
EDITORIALS

Table 1. Diagnosis specific studies of rural-urban morbidity

\begin{tabular}{|c|c|c|}
\hline & United Kingdom & International \\
\hline Urban > rural & $\begin{array}{l}\text { Anxiety/depression/phobia (Meltzer et al. 1995) } \\
\text { Schizophrenia (McCreadie et al, 1997) }\end{array}$ & $\begin{array}{l}\text { Neuroses (Keatinge, } 1988 \text { (Eire)) } \\
\text { Anxiety and depression (Crowell et al, } \\
1986 \text { (Carolina)) }\end{array}$ \\
\hline Urban < rural & & $\begin{array}{l}\text { Schizophrenia (Thornicroft et al, } 1993 \\
\text { (Italy)) } \\
\text { Depression (Cheng, } 1989 \text { (Taiwan)) } \\
\text { Depression (Orley \& Wing, } 1979 \\
\text { (Uganda v. Camberwell)) }\end{array}$ \\
\hline Urban=rural & $\begin{array}{l}\text { OCD/Panic/Psychosis (Meltzer et al, 1995) } \\
\text { Depression (Brown \& Prudo, } 1981 \\
\text { (Hebrides v. Camberwell)) }\end{array}$ & Schizophrenia (Keatinge, 1988 (Eire)) \\
\hline
\end{tabular}

was not defined but left to the impression of the large numbers of interviewers carrying out home-based assessments. The study by McCreadie et al (1997) demonstrates that the prevalence of schizophrenia in a rural Scottish area is half that in deprived inner-city Camberwell. The authors point to the difficulty of generalising these findings even within the UK and replications in other parts of the country are required. A study examining the rates of personality disorder presenting to urban and rural general practices in the Nottingham area found a higher rate in urban areas solely accounted for by the explosive/sociopathic category, with similar rates across the areas in all others (Casey \& Tyrer, 1990).

\section{Ethnicity/race}

The impact of race on the prevalence of schizophrenia is well-documented (Leff, 1988). McCreadie et al (1997) have demonstrated in their UK study that the large difference in prevalence of schizophrenia between their rural and urban areas was almost entirely accounted for by the high prevalence in urban non-Whites, with little difference between urban and rural Whites (despite socio-economic differences). Although numbers of non-Whites in Britain's rural areas are typically small, the difficulties such individuals face may be considerable (Sherlock. 1994) but little is known about the effects on their mental health.

\section{Occupation/social class}

The influence of factors associated with social class on levels of psychiatric morbidity is well described (Thornicroft, 1991), but most studies have been carried out in urban areas. Studies or rural population examining this relationship are rare. Romans-Clarkson et al (1990) found a similar relationship between socio-economic states and morbidity in New Zealand women from rural and urban areas. However, Thornicroft et al (1993) found no relationship between a variety of service utilisation measures and employment or education levels in a rural population, although a significant association was found in a neighbouring urban sample.

In a UK study, McCreadie et al (1997) found similar levels of gainful employment and educational qualifications among people with schizophrenia in rural and urban areas.

Farmers are an almost exclusively rural occupational group with a particularly high suicide risk, which ranks fourth in order of risk by occupation and now accounts for the second most common cause of death for male farmers under 45 (accidents being the first). In terms of absolute numbers of suicides, farmers have the highest numbers of any occupation in the UK. These high rates are related to depressive illness and access to means, particularly firearms (Malmberg et al, 1997). The Samaritans and National Farmers' Union have recently been targeting preventative efforts at this high-risk group.

\section{Geographical and clustering effects}

In addition to the international differences in distribution of psychiatric morbidity across rural and urban areas specific clusters of high levels of specific disorder have been described. Taking, for example, the prevalence of schizophrenia. specific areas of very high and very low prevalence have been described throughout the world with up to 20 -fold variations in rates (Torrey et al, 1984; Torrey, 1987). The differences described do not show any consistent rural-urban patterns, and are on the whole far greater than any differences in morbidity which 
have emerged from comparisons of rural and urban areas.

\section{Proxy/indicators of morbidity and need}

Given the dearth of direct information on morbidity and service requirements, are there any indirect indicators of mental health needs which can reliably guide us? Indices of deprivation are increasingly applied in resource allocation, but their validity in rural areas has been challenged (Jessop, 1992). The commonly used deprivation indices have been developed in urban areas, and the relationship between these indices or components of them and psychiatric morbidity may be different in rural areas, as found by Thornicroft $e t$ al (1993). Several studies have documented differences between rural and urban areas in the relationship between mental illness and factors such as social support, life events and physical illness (Brown \& Prudo, 1981; Carpiniello et al, 1989; Romans-Clarkson, 1990; Bowling \& Farquhar, 1991).

\section{Service provision}

More consistent findings emerge from the examination of service issues. Primary care appears to be more involved in mental health in the rural areas around Nottingham (Seivewright et al 1991). Patients had more contact with psychiatrists in urban areas (including more contacts because of physical complaints) and patients in rural areas had more contact with general practitioners. Psychotropic drug use and admission rates were higher in the urban area. Very similar findings were reported by Sullivan et al (1996) in Mississippi, who concluded that the results were most likely to be due to the lesser availability and accessibility of services in the rural areas. A study of schizophrenia in indigenous populations in two areas of Eire (Keatinge, 1988) showed the same incidence in urban and rural areas but the first admissions in the rural group occurring at a later and more chronic stage. Another Irish study (Keatinge, 1987) showed a tendency to under-report neurotic, though not psychotic, symptoms in rural areas and a more negative attitude to psychiatric facilities in rural areas leading to a higher threshold for seeking help. A UK survey of general practitioners' attitudes demonstrated perceived inaccessibility of mental health services in rural areas (Stansfield et al, 1992). Hall (1988) showed that distance from services was a significant predictor of utilisation of mental health services. Cuffel (1994) has shown higher thresholds for admissions to psychiatric hospital in rural than urban areas. A Swedish study
(Gyllenhammar et al, 1998) found that, given similar and equally accessible services in rural, suburban and urban areas, the number and nature of emergency psychiatric presentations were the same.

Given the increasing role of primary care in looking after the mentally ill it is important to appreciate the relative inaccessibility of primary care facilities as well as social services and voluntary sector facilities in rural areas (Bentham \& Haynes, 1986: Fearn, 1987). Findings of increased burden on families and informal carers of people with schizophrenia in rural areas (Martyns-Yellowe, 1992) may also be a reflection of the same service issues. The lack of community facilities for people in rural areas has been highlighted by various non-Government organisations who are beginning to focus particular attention on rural mental health issues (e.g. Ruralminds, Rural Stress Information Network, Samaritans).

The paper by Smith \& Ramana (1998) provides further evidence of the unequal distribution of resources which results from historical differences in provision and unquestioning urban focus, rather than an analysis of needs.

Resource allocation and service planning must reflect the difficulties and peculiarities of providing secondary care service in rural areas. The problems facing users and primary care in accessing services and the difficulties for secondary care in providing them are well described (Sherlock, 1994) but the quantitative data and cost implications are lacking (Pullen \& Kendrick, 1995) although these may be significant (Watt et al, 1994).

\section{Towards a better understanding of rural mental health issues}

The international variation in urban/rural patterns of morbidity demonstrates the need to interpret these data in their cultural and social context. In the UK, overall psychiatric morbidity appears to be greater in urban areas. This must be interpreted with caution as we still know little about patterns of individual disorders and there is some evidence of greater hidden morbidity and higher thresholds for reporting symptoms in rural areas. Furthermore, greater accessibility to services in urban areas may lead to resourceled drift of users to those areas. The size of even the largest rural/urban differences is small compared with the effects of other factors such as race, national or more local geographical differences and social class.

The probable lesser prevalence of disorders in rural areas could be due to lower incidence or a more favourable course of disorders, or both. It is impossible to distinguish which process is 
operating but if there is some "illusive quality about rural environments" (Crowell et al, 1986) which confers protection or better outcome, we should make efforts to identify it through research and preserve it where it exists.

As the organisational requirements and costs of rural mental health service provision are also inadequately defined, it is inevitable that the already disjointed systems for the funding of community care in rural areas will depend on historical and arbitrary judgements. We need UK-based research giving detailed data on detected and undetected morbidity and associations with indices of deprivation in rural areas which could provide valid proxies. This needs to be coupled with quantitative studies of mental health service requirements at primary and secondary care levels to ensure that the mentally ill in rural areas are not forgotten in the drive to improve the mental health of the nation.

\section{References}

Bentham. G. \& HaYnes, R. (1986) A raw deal in remoter rural areas? Family Practitioner Services, 13, 84-87.

BOWLNG, A. \& FARgUHAR, M. (1991) Associations with social networks. social support, health status and psychiatric morbidity in three samples of elderly people. Socia Psychiatry and Psychiatric Epidemiology, 26, 115-126.

BROWN, G. W. \& PRUDO, R. (1981) Psychiatric disorder in a rural and an urban population 1. Aetiology of depression. Psychological Medicine, 11, 581-599.

Carpiniello. B. Carta. M. G. \& Rudas, N. (1989) Depression among elderly people. Acta Psychiatrica Scandinavica. 80, 445-450

CASEY, P. R. \& TYRER, P. (1990) Personality disorder and psychiatric illness in general practice. British Journal of Psychiatry. 166, 261-265.

CHEnG, T. A. (1989) Urbanisation and minor psychiatric morbidity. Social Psychiatry and Psychiatric Epidemiology. 24. 309-316.

CLOKE. P. (1977) An index of rurality for England and Wales. Regional Studies, 11. 31-46.

Crowell, B. A.. George, L. K., Blazer, D., et al (1986) Psychosocial risk factors and urban/rural differences in the prevalence of major depression: British Joumal of Psychiatry, 149. 307-314.

Curpel. B. J. (1994) Violent and destructive behaviour among the severely mentally ill in rural areas: evidence from Arkansas' community mental health system. Community Mental Health Journal, so, 495-504.

FEARN, R. (1987) Rural health care: a British success or a tale of unmet need? Social Science and Medicine, 24. 263-274.

GuINNESS, E. A. (1992) Patterns of mental illness in the early stages of urbanisation. British Journal of Psychiatry. 160 (suppl. 16), 4-72.

Gruenhammar, C., Lundin, T., OTto, U., et al (1988) The panorama of psychiatric emergencies in three different parts of Sweden. European Archives of Psychiatry and Neurological Sciences, 237, 61-64.

HALL. G. (1988) Monitoring and predicting community mental health centre utilisation in Auckland. New Zealand. Social Science and Medicine, 26. 55-70.

JEsSOP, E. G. (1992) Individual morbidity and neighbourhood deprivation in a non-metropolitan area. Journal of Epidemiology and Community Health. 46. 543-546.
KeAtinge, C. (1987) Community factors influencing psychiatric hospital utilisation in rural and urban Ireland. Community Mental Health Joumal, 23. 192203.

- (1988) Psychiatric admissions for alcoholism, neuroses and schizophrenia in rural and urban Ireland. International Journal of Social Psychiatry, 34, 58-69.

LEE, C. K., KWAK, Y. S., YAMAMotA, J., et al (1990) Psychiatric epidemiology in Korea - Part II: Urban and rural differences. Journal of Nervous and Mental Disease, 178, 247-252.

LEFF, J. (1988) Psychiatry Around the Globe: A Transcultural View. London: Gaskell.

LEWIS, G. \& BOOTH, M. (1994) Are cities bad for your mental health? Psychological Medicine, 24, 913-915.

Malmberg, A. HaWton. K. \& Simkin, S. (1997) A study of suicide in farmers in England and Wales. Journal of Psychosomatic Research, 43, 107-111.

MARTYNS-YELOWE, I. S. (1992) The burden of schizophrenia on the family. A study from Nigerla. British Joumal of Psychiatry. 161, 779-782.

MCCreadie, R. G., Leese, M., Tilak-Singh, D., et al (1997) Nithsdale. Nunhead and Norwood: similarities and differences in prevalence of schizophrenia and utilisation of services in rural and urban areas. British Journal of Psychiatry. 170, 31-36.

McGee, R. Standton, W. \& Feehan, M. (1991) Big cities, small towns and adolescent mental health in New Zealand. Australian and New Zealand Journal of Psychiatry. 26. 338-342.

Meltzer, H., Gill, B., PetTicrew, M., et al (1995) The Prevalence of Psychiatric Morbidity Among Adults Living in Private Households. London: Office of Population Censuses and Surveys.

ORLEY, J. \& WING. J. K. (1979) Psychiatric disorders in two African villages. Archives of General Psychiatry. 36. 513-520.

Pullen, I. \& KendRICK. T. (1995) Peer commentaries on 'An evaluation of community-based psychlatric care for people with treated long-term mental illness'. British Journal of Psychiatry, 167, 38-40.

Romans. S. E.. WAlton. V. A. Herbison, G. P., et al (1990) Social networks and psychiatric morbidity in New Zealand women. Australian and New Zealand Joumal of Psychiatry, 26, 485-492.

Romans-Clarkson, S. E., Walton, V. A., Herbison, P. B., et al (1990) Psychiatric morbidity and women in urban and rural New Zealand: Psychological correlates. British Journal of Psychiatry. 166, 84-91.

RURAL DEVELOPMENT COMMISSION (1994) Rural Development Areas 1994. London: Department of Environment.

SeIvewright, H.. TYReR, P.. CASEY, P.. et al (1991) A threeyear follow-up of psychiatric morbidity in urban and rural primary care. Psychological Medicine, 21, 495503.

SHERLOCK. J. (1994) Through the Rural Magnifying Glass. London: Good Practices in Mental Health.

ShuCksmrth, M. (1990) The Definition of Rural Areas and Rural Deprivation. Report to Scottish Homes. Aberdeen: Department of Land Economy. University of Aberdeen.

-. RoBerTS. D.. ScotT, D.. et al (1996) Disaduantages in Rural Areas. Salisbury: Rural Development Commission.

Stansfield, S. A. Leek. C. A. Travers, W., et al (1992) Attitudes to community psychiatry among urban and rural general practitioners. British Journal of General Practice. 42, 322-325.

SMrTH, A. J. \& RAMANA, R. (1998) Mental health in rural areas: experience in South Cambridgeshire. Psychiatric Bulletin. 22. 280-284. 
Sullivan, G. JACKSON C. A. \& SPRITZER, K. L. (1996) Characteristics and service use of serious mentally ill persons living in rural areas. Psychiatric Services. 47. $57-61$.

THORNICROFT, G. (1991) Social deprivation and rates of treated mental disorder - Developing statistical models to predict psychiatric service utilisation. British Journal of Psychiatry. 168, 475-484.

-. Bisoff, G.. DE Salvia, D., et al (1993) Urban-rural differences in the associations between social deprivation and psychiatric service utilisation in schizophrenia and all diagnoses: A case-register study in northern Italy. Psychological Medicine, 23, 487-496.

TORREY, E. F. (1987) Prevalence studies in schizophrenia. British Journal of Psychiatry, 160. 598-608.

-. MCGUIRE, M.. O'HARE, A., et al (1984) Endemic psychosis in western Ireland. American Journal of Psychiatry. 141, 966-969.

WATT. I. S. (1995) Health Needs of Rural Residents (Review) Occasional Paper 71. London: Royal College of General Practitioners.
- Franks, A. J. \& SHELDON, T. A. (1993) Rural health and health care - Unjustifiably Neglected in Britain. British Medical Journal, 306, 1358-1359.

- - - \& - (1994) Health and health care of rura populations in the UK: Is it better or worse? Journal of Epidemiology and Community Health, 48, 16-21.

WEBB, S. D. (1984) Rural-Urban differences in mental health. In Mental Health and the Environment (ed. H. I Freeman). Edinburgh: Churchill Livingstone.

*Alain Gregoire, Consultant/Honorary Senior Lecturer in Psychiatry, Salisbury Health Care and Southampton University. Old Manor Hospital, Salisbury, Wiltshire SP2 7EP, and Graham Thornicroft, Professor and Director of PRiSM. Institute of Psychiatry. London

*Correspondence

\section{The Royal College of Psychiatrists Journal of ('ontimuing Professional Development}

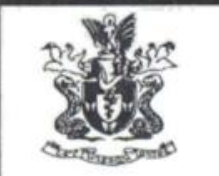

Subscription rate for Volume 4, 1998

(6 issues starting January):

Europe, including UK $£ 73.00$

USA US\$120.00 Elsewhere $£ 73.00$

Full airmail $£ 6 / \$ 10$ extra

$A P T$ with CPD registration $£ 85.00$

To enter your subscription or to obtain a sample copy of APT, contact:

Publications Subscription Department, Royal Society of Medicine Press Limited, PO Box 9002, London WIM 0ZA, UK. Tel: +44(0)171 290 2927/8; Fax: +44(0)171 2902929

College members wishing to receive APT and register for $C P D$ should contact the Registration Department, Tel: $+44(0) 171$ 2352351

\section{Psychiatric Treatment}

\section{Contents of the May 1998 issue}

Drug treatment for early Alzheimer's disease. $R$. Bullock

Maternal mental illness and mother-child relations.

D. M. Foreman

Influence of parental eating disorders in children. $H$. Woolley, R. Wheatcroft \& A. Stein

Occupational factors and unexplained physical symptoms. M. Hotopf

Psychiatric aspects of diabetes mellitus. $P$. Trigwell \& R. Peveler

Teaching psychiatry to medical undergraduates. S. Curran \& P.C. Bowie

Teaching child and adolescent psychiatry to medical undergraduates. A. E. Worrall-Davies

Teaching general psychiatry to medical undergraduates. $T$. Hughes \& C. Williams

Teaching old age psychiatry to medical undergraduates.

S. Curran \& P. C. Bowie 